\title{
Daily behavioural activity patterns and reproductive ecology of urban rhesus macaques (Macaca mulatta) in human dominated landscape and its implication in management
}

Ishita Ganguly*

Block-J1, Amity Institute of Forestry and Wildlife, Amity University, Sector 125, Noida201313 (Uttar Pradesh), India

Netrapal Singh Chauhan

Block-J1, Amity Institute of Forestry and Wildlife, Amity University, Sector 125, Noida201313 (Uttar Pradesh), India

${ }^{*}$ Corresponding author. E-mail: ishitaganguly23@gmail.com

\begin{abstract}
We observed behavioural activity patterns, daily movements and reproductive ecology (birth rate, death rate, breeding seasons, mating) of urban rhesus macaques (Macaca mulatta) in man-made environment after their reintroduction in Asola-Bhatti Wildlife Sanctuary, Delhi, India using instantaneous sampling or scan sampling method. The daily activity patterns of rhesus macaques inhabiting in the sanctuary were observed from 6:00 $\mathrm{h}$ to $18: 00 \mathrm{hrs}$ per day from March 2016 to June 2017. The percentage of each activity was estimated quantitatively and birth rate per female per troop in a year was calculated in total 21 troops of rhesus macaques. Macaques adopted different time slot for maximum utilization of food and space available and we estimated the percent time spent of each activity pattern and their variations in a particular geographic area. Daily average distance travelled was $1.89 \mathrm{~km} /$ day and it was restricted to the feeding platforms. Mortality was incredibly low $(0.17)$ and high reproductive success was in females per troop. Number of females per troop was 4.48 on average, mean birth rate was calculated 2.20 per female per troop in a year, gestation length 160 days on average. Breeding seasons were April to June and late August to October, although there was no seasonal variation in daily activity pattern and movement ranges throughout the year in the sanctuary. Our study recommendation will help in reducing human-macaque conflicts in urban areas and will serve as a potential source of information of ecology, behaviour of urban rhesus macaques and their management.
\end{abstract}

Keywords: Daily activity, Human-macaque conflict, Management, Rhesus macaque Reproductive ecology

\section{INTRODUCTION}

Behavioural pattern and activity, both the terms have been synonymously used in several studies and these terms were generally incorporated to depict social and individual activities in a macaque troop. Behavioural responses of primate species to habitat modification, daily movement patterns are adaptations to their newly introduced environments. The foremost requirement for primate management is to study the behavioural responses of species in concern to the changes in their environment. Focusing on animal behaviour in the appropriate social contexts will help to develop strategic devices for the management of wildlife species in their habitats (Singh and Kaumanns, 2014). Daily activity patterns in different primate species have been studied earlier in both, wild and in captivity (Lindburg, 1971; Southwick et al., 1982; Malik, 1986; Chalise, 1999). But there

\section{Article Info}

DOI: 10.31018/jans.v10i4.1886 Received: September 7, 2018 Revised: September 23, 2018 Accepted: October 5, 2018

\section{How to Cite}

Ganguly, I. and Chauhan, N. S. (2018). Daily behavioural activity patterns and reproductive ecology of urban rhesus macaques (Macaca mulatta) in human dominated landscape and its implication in management. Journal of Applied and Natural Science, 10 (4): 1101-1108 
serve the purpose of effective management. Conserving behavioural traits of an animal is worthy of conservation itself in both, natural and man-made environment. Movements of an animal in a day, distance travelled, the purpose of travel, energetics and behaviour are important aspect of study in spatial ecology (Sennhenn-Reulen, 2017). Behavioural manipulations of animals in changed environment, their reproductive patterns, predation pressures, habitat modifications are important aspects to study from ecological point of view for the need of conservation (Sutherland, 1998). Sexual behaviours and reproductive activities have evolutionary significance in ecology and it balance cost and effectiveness (Jolly, 1985; Keverne, 1989). The behaviours associated with mating, copulation, social grooming, mother-infant interaction and lactation for young individuals associated with reproduction and it is speciesspecific. To understand the environmental changes on reproductive patterns and its adaptive value is extremely important for wildlife management (Dunbar, 1988). Female rhesus macaques very rarely leave their natal groups (Fooden, 2000). Mother-infant interactions in primates indicates the role of mothers in social troops (Altmann, 1980; Maestripieri, 2001). This mechanism can be species-specific or vary among the individual troops because of their immediate local ecology which can create larger or smaller opportunities for post-natal care and development (Charmantier and Garant, 2005, Dufour and Sauther, 2002). Our aim of this study was to investigate the daily behavioural patterns including sexual behaviours, movements and reproductive ecology of urban rhesus after their reintroduction in Asola-Bhatti Wildlife Sanctuary, South division of forest, Delhi, a human-dominated landscape. Wildlife management required an active intervention for commensal population of non-domesticated urban macaque species in man-altered landscape and we are the first researcher to gather vital information on activity patterns of rhesus macaques in this sanctuary.

\section{MATERIALS AND METHODS}

Study area: Asola-Bhatti wildlife sanctuary is situated in south Delhi district along with Delhi and Haryana interstate border ( $N 28^{\circ} 24^{\prime} 52^{\prime \prime}-28^{\circ} 29^{\prime}$ $45^{\prime \prime}$ and $\left.E 77^{\circ} 11^{\prime} 32^{\prime \prime}-77^{\circ} 16^{\prime} 13^{\prime \prime}\right)$ and the total area covers around 6,874 ha (Fig.1). The forest area is located at the foothill of world's oldest mountain range, called Aravalli and about $16 \mathrm{~km}$ long and $4.3 \mathrm{~km}$ wide, elevation ranged from $774-$ $948 \mathrm{ft}$. This forest area is surrounded by hilly area with shrubs, lower diameter stunted trees, moderately density forest cover and adjacent to urban areas such as Delhi-Haryana interstate border region, Sangam Vihar, Faridabad (Surajkund road), Pali village, Sat beri, Dera gaon, Fatepur beri and
Anangpur village area at the back side of the forest. This protected area has semi-arid vegetation pattern, presence of xerophytic plants and large open, deep pits in the ground all over the sanctuary and the biggest water filled pit has been termed as "Neeli Jheel" which is situated 3km away from Gate No. 7 of forest exit, where the urban monkeys are released after capture from urban areas and translocation into the forest area. Maximum temperature in summer varied from $43-47^{\circ} \mathrm{C}$ and in winter months $\pm 6^{\circ} \mathrm{C}$ with average annual rainfall \pm 617 $\mathrm{mm}$.

Study troops: A 'troop' was consisted of adult males, adult females, sub-adult males, sub-adult females, infants and juveniles and all individuals in a certain group was found to move together and mate within individual group members. We observed a total of 21 troops of rhesus macaques, from close distance $<10 \mathrm{~m}$ with naked eye and collected data on behavioural patterns from 06:00h to $18: 00 \mathrm{~h}$ daily during March 2016 to June 2017.

Data sampling: Instantaneous sampling or scan sampling (Altmann, 1974) was used to gather information on behavioural profiles. Group scans were taken on all visible members of the group for a period of $5 \mathrm{~min}$ at every 10 -min interval. We recorded 14,840 scan samples of different behaviours and percent time spent on each activity was calculated. We recorded a minimum 12 entries on the focal individual in an hour and recorded total 11,571 focal samples and calculated for each activity. We studied some behavioural traits which will help to solve our research question. Movements of animals, daily distance travelled were tracked by GPS (GPS Garmin $72 \mathrm{H}$ ) and point sampling method. Position of primates were recorded at each encounter and the distance was measured.

In our study, we have studied certain behavioural

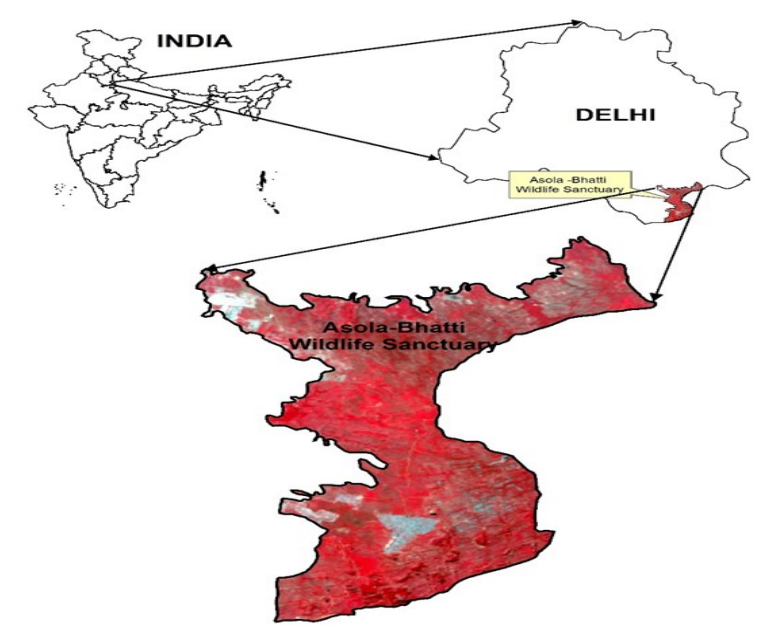

Fig.1. Location map of study area, Asola-Bhatti Wildlife Sanctuary, Delhi. 
pattern related to reproduction such as grooming, fighting, chasing, aggression and lactation.

The following Activities/Behaviours were recorded to study activity pattern of relocated rhesus macaques:

Feeding- Collection and accumulation of provisioned food items given by public and supplementary food items given by forest department

Grooming-Taking care of own body parts, furs and other individuals of troop by physical contact and touch, Nursing

Aggression- Showing any kind of threats, upright tail, redness of face, bare teeth display and highly intensive movements with energy, Agonistic behaviour, Fighting, Chasing

Running-Highly mobilised movements for selfhelp or for others

Snatching-Taking any stuff from various sources forcefully especially food items and running off Attacking- Include going close, slapping, jumping at and pulling, Injury, Bite, Throwing items on each other or on human

Vocalization- Any kind of call for unknown reasons

Natural foraging- Natural tendency to consume plant resources and parts (leaves, fruits, flowers, bark, piths etc.) and foraging natural food habits exclusively on trees.

Playing- Jumping on trees, ropes and falling here and there with any object without hurting any individuals of troops (Observed in infants and juveniles).

Gesture- Any posture or movements at resting period

Conflict- Inter troop fighting between males, negative interactions with human during providing food

All the 11 categories of behaviour recorded were estimated based on relative distribution of their percentages. Each activity record was analysed by summation of all records of all categories and expressing them as percentage of the total number of records collected per day by scan sampling method.

Equation:

$A_{C}=(A i / A) \times 100$

Where, $A_{C}=$ Percentage of activity; $A i=$ Total number of observation by scan sampling method of any activity per day; $A=$ Total number of observations of all the records of activities per day

ANOVA was run to analyse the differences among different activity patterns.

We observed the pattern of movements, daily path travelled and its possible causes and behaviour. We recorded their movements each day and studied the number of reasons of their movements: 1. Natural foraging, 2. Supplementary feeding, 3. Food provisioning by public, 4. Negative interactions with human, 5. Social Play, 6. Intra-troop movements and 7. Inter-troops movements.

We collected information on sexual behaviours for 12 month period per group on the and recorded number of births. We collected quantitative data on sexual behaviour via sampling ad libitum per as Altmann (1974). We recorded the births in the group in $\leq 15$ day from their occurrence because it is difficult to have the exact date of birth in natural populations. We calculated the birth rate on the number of births in all the groups in a year (Rajpurohit et al., 1994).

The following terms are used in text;

Birth season: The periods of a year when maximum numbers of births do occur

Birth rate (b): Number of infants born in a year to a female in a given population sample

Equation

$\mathrm{b}=\mathrm{It} / \mathrm{Ft}$

Where, $b=$ birth rate, It $=$ Total number of infants born in one year, $\mathrm{Ft}=$ Total number of reproductive females in a sample throughout the year

The following terms were used in the text in explaining Death rate (Blomquist, 2013).

Death rate: Number of offspring died in a year in a given population sample

Equation used to calculate: death rate $=(1-$ survived/enter-removed)

Ethical approval: We took permission to conduct study in fields on primates from Government and after receiving official approval from Chief Wildlife Warden, Forest department, Govt. of NCT Delhi, we surveyed the field and studied behaviours of rhesus macaques from close distance. AsolaBhatti Wildlife Sanctuary is a Government land and we took permission to access the land for study on primates. No animals were sacrificed or harmed for this study.

\section{RESULTS}

Behavioural activity patterns: The daily activity patterns of rhesus macaques inhabiting in the sanctuary from 6:00 h to $18: 00 \mathrm{hrs}$ per day indicated that from June 2016 to May 2017. Macaques adopted different time slot for maximum utilization of food and space available and we estimated the percentage of each activity pattern and their variations with time (Fig.2). Frequency of activity increased between 12:00 noon to 15:00hrs in each category (Feeding, grooming, aggression, running, snatching, attacking, vocalization, gesture and conflict) except natural foraging and social playing. We observed maximum natural feeding and foraging (17.27\%) between 7:00-8:00 hrs and social play was observed maximum $(9.82 \%)$ in early morning between 6:00-7:00 hrs and late afternoon $(9.55 \%)$ between 16:00-17:00hrs. We recorded the supplementary feeding activity of rhesus macaques quantitively and mean percent feeding was estimated as $8.33 \pm 0.86$ and T-test analysis showed significant difference in feeding activity 
Ganguly, I. and Chauhan, N. S. / J. Appl. \& Nat. Sci. 10 (4): 1101-1108 (2018)

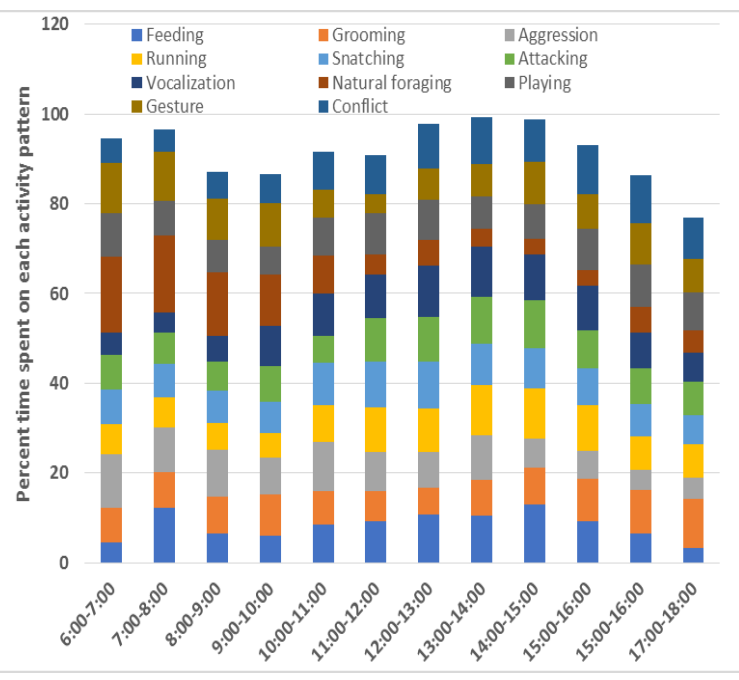

Fig.2. Behavioural pattern of relocated urban rhesus macaque in the sanctuary, Delhi.

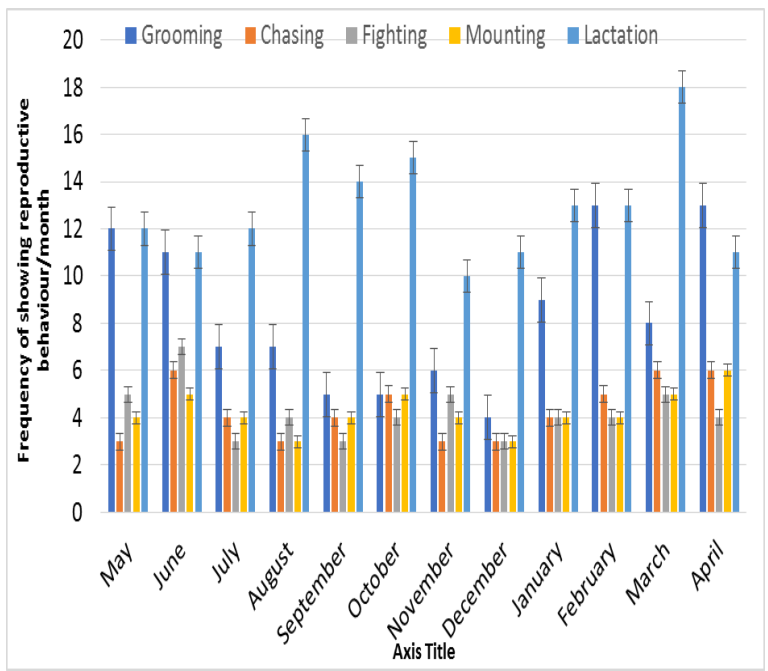

Fig.3. Sexual behavioural pattern in relocated rhesus macaques monthly from June 2016 to May 2017.

(percentage) in all the different hours per day $(T=9.53, P<0.001)$. Peak hours of feeding were noted as 12:00-13:00hrs (10. 67\%), 13:00-14:00 hrs $(10.39 \%)$ and $14: 00-15: 00$ hrs $(12.96 \%)$ on average per day throughout the year. Grooming activity was recorded thoroughly throughout the day and mean percent grooming was estimated as $8.32 \pm 0.38$. T-test analysis showed that grooming activity varied significantly with change in hours $(T=21.61, P<0.001)$. Maximum occurrence was observed in the morning hours till 10:00hrs and evening between 17:00-18:00hrs. Allogrooming and auto-grooming behavioural activities were recorded and allo-grooming behaviour was maximum $(67.13 \%)$ in our study. Adult male to fertile female grooming behaviour was observed in the breeding months (April, May, June) and postnatal grooming was observed between adult female to juveniles throughout the year. Macaques were observed to display more aggressive behaviour in the early morning between 6:00-7:00 hrs (11.86\%), 7:00-8:00hrs (10.16\%) and 8:009:00hrs (10.38\%). Running activity increased between 12:00-15:00hrs per day and this behaviour was supported and correlated with supplementary feeding hours. Snatching behaviour was observed maximum in between 11:00-13:00 hrs (10.54\%) per day. Attacking was maximum in between 13:00-15:00 hrs and food was the principal component responsible for this behavioural pattern. Vocalization was recorded in between 12:0014:00 hrs in maximum frequency. Gesture as such sitting, sleeping, resting was observed maximum in the early morning and movements increased with the day length.

Conflict was an interesting phenomenon and we recorded intra-troop and inter-troop conflict behaviour of macaques. Summary of descriptive statistics is given in Table 1. We also recorded the incidences of feeding, provoking and conflicts in rhesus macaques. ANOVA analysis showed there was significant difference in three types of activities with monthly changes $(F=7.41, \quad d f=11$, $\mathrm{P}=0.002$ ). Independent t-test analysis showed significant difference in average feeding events in each month ( $\mathrm{t}=20.99, \mathrm{P}<0.001$ ), provoking incidences $(t=15.80, P<0.001)$ and conflict incidences $(t=10.52, P<0.001)$ in each month in the sanctuary. Conflict was positively correlated with provoking $(R=0.04, P<0.05)$ and negatively correlated with feeding $(R=-0.27, P<0.05)$.

Their locations using GPS, troop ranges, daily average distance travelled by macaques recorded during study period are given in Table 2. Average daily movement range was recorded $1.89 \mathrm{~km} /$ day by rhesus macaques in the sanctuary. In the early morning before 6:00 hours, movements were fast due to opportunistic feeding, between 6:00-9:00 hours movements were moderate to slow except social play activity of juveniles. After 9:00 hours, macaques transformed into very fast-moving animals and engaged in collection and gathering of food, competition for resources, snatching, attacking and damaging activities and this behaviour continued till 16:00 hours per day in a year. Later in the evening phases they became slow and sluggish. We could not find any significant seasonal differences $(P>0.05)$ in daily movement pattern.

Reproductive ecology: Reproductive behavioural pattern was observed and ANOVA showed significant difference in each behaviour throughout the year $(P<0.001)$ in our study (Table 3$)$. We recorded the range of behaviours related to reproduction and mother-infant relationship during feeding and grooming. The frequency of reproductive behaviours throughout the year and observed differences are given in Fig. 3 .

We calculated the number of births/female in 21 troops of rhesus macaques in the sanctuary. 
Ganguly, I. and Chauhan, N. S. / J. Appl. \& Nat. Sci. 10 (4): 1101-1108 (2018)

Table 1. Summary of behavioural observations in relocated rhesus macaques.

\begin{tabular}{lllll}
\hline Behavioural activity & $\begin{array}{l}\text { Number of } \\
\text { observed }\end{array}$ & $\begin{array}{l}\text { months } \\
\text { queancy }\end{array}$ & $\begin{array}{l}\text { fre- } \\
\text { quen Dev }\end{array}$ & $\begin{array}{l}\mathbf{9 5 \%} \\
\text { interval (Cl) }\end{array}$ \\
\hline Artificial Feeding & 12 & 11.58 & 2.06 & $(10.090,13.082)$ \\
Social Grooming & 12 & 11.04 & 3.76 & $(9.54,12.54)$ \\
Aggression & 12 & 9.58 & 1.63 & $(8.088,11.080)$ \\
Running & 12 & 10.27 & 1.29 & $(8.773,11.765)$ \\
Snatching & 12 & 6.87 & 2.25 & $(5.380,8.372)$ \\
Attacking & 12 & 6.03 & 2.18 & $(4.542,7.533)$ \\
Vocalization & 12 & 7.99 & 2.05 & $(6.503,9.494)$ \\
Natural Eating and foraging & 12 & 10.93 & 2.39 & $(9.436,12.427)$ \\
Playing & 12 & 10.14 & 4.08 & $(8.64,11.63)$ \\
Gesture & 12 & 7.88 & 3.01 & $(6.391,9.382)$ \\
Conflict & 12 & 7.56 & 2.66 & $(6.068,9.060)$ \\
\hline
\end{tabular}

Table 2. Reproductive behaviour pattern in relocated urban rhesus macaques

\begin{tabular}{lllllll}
\hline Variables & Total occurrence & $\begin{array}{l}\text { Number } \\
\text { months observed }\end{array}$ & $\begin{array}{l}\text { Rate } \\
\text { occurrence }\end{array}$ & $\begin{array}{l}\mathbf{9 5 \%} \text { Confidence } \\
\text { interval (CI) }\end{array}$ & P-Value \\
\hline Grooming & 100 & 12 & 8.33 & $6.78,10.13$ & $0.000^{*}$ \\
Chasing & 52 & 12 & 4.33 & $3.23,5.68$ & $0.000^{*}$ \\
Fighting & 51 & 12 & 4.25 & $3.16,5.58$ & $0.000^{*}$ \\
Mounting & 51 & 12 & 4.25 & $3.16,5.58$ & $0.000^{*}$ \\
Lactating & 156 & 12 & 13.0 & $11.04,15.20$ & $0.000^{*}$ \\
\hline
\end{tabular}

${ }^{*} P$ value $<0.05$ is considered significant

Mean number of total birth was 9.38, whereas mean deaths were 1.33 , birth rate 2.20 per female/troop/year and death rate 0.17 per year in 21 troops under study (Table 3 ). Average number of individuals per troop was 31 including adult male, female, sub-adult male, female, infants and juveniles and number of mating pair observed was $6.69 \pm 1.2$ per month, average time spent in copulatory mounts was $1.76 \pm 0.67$ minutes. Mating was observed throughout the year, April to June each year was designated as breeding months followed by few more births post monsoon during late August to September. We observed mother-infant relationship through behavioural study. Maximum frequency of lactation behaviour was recorded in the breeding seasons though it was seen throughout the year. Mothers did not allow the infants to fed on leaves, soils or anything else other than breast feeding. Social grooming was observed between adult male to adult female during birth months before parturition and adult female to juveniles after birth to six months of age. Adult females spent $39.5 \%$ time in auto-grooming, 22.07 $\%$ time in grooming male partners and $38.43 \%$ time in grooming offspring.

\section{DISCUSSION}

Activity pattern: Studying animal behaviour has a significant role in management of wildlife species and conservation biology. Behavioural studies focus on individual or social groups and unfold the mechanisms of certain behavioural patterns, causes of such behaviour and adaptive significance of behaviours in concern and it helps in developing methods and devices to manage the species (Singh and Kaumanns 2005). Spatial ecology information is crucial for wildlife management and behavioural research. The application of global positioning system (GPS) has improved the data collection process (Kays et al., 2015), which provides wildlife researchers an opportunity to animal behaviour in geo-spatial platform. The use of GPS has become more popular in primate field studies (Osborne and Glew, 2011; Sterling et al., 2013). In our study, locations of primates using GPS during field observations and behavioural activity patterns of rhesus macaques after their relocation into Asola-Bhatti Wildlife Sanctuary from urban areas indicated that the randomly captured macaques and released into this sanctuary intermittently throughout the year socialized with each other and reconstructed troops (multi-male/ multi-female) within this sanctuary and propagated thoroughly. There are generally two types of macaques, those who inhabit in forested habitat and others in urban areas and there are striking differences in population size, movement range and behavioural patterns in both types (free-ranging and urban population). Rhesus macaques in our study typically showed the characteristics of urban macaques in behavioural aspect. Proximity of human settlements (Sanjay colony, Bhatti Village, Sangam Vihar, Asola housing complex, Chatterpur area) to Asola-Bhatti Wildlife Sanctuary , southern division of forest, Delhi (NCT) and supplementary feeding played influential role in decision making process of daily activity pattern. We followed the troops from morning to evening and identified feeding patches and resting sites in the sanctuary. Food distribution pattern had a great influence on movements and behaviour of macaques in our study. Rhesus macaques were ob- 
Ganguly, I. and Chauhan, N. S. / J. Appl. \& Nat. Sci. 10 (4): 1101-1108 (2018)

Table 3. Births and birth rate in 21 troops of rhesus macaque from 2016-2017 in ABWLS

\begin{tabular}{cccccc}
\hline Troops & Adult female & Births & Birth rate & Deaths & Death rate \\
\hline 1 & 4 & 9 & 2.25 & 0 & 0 \\
2 & 3 & 7 & 2.33 & 0 & 0 \\
3 & 3 & 8 & 2.66 & 0 & 0 \\
4 & 4 & 9 & 2.25 & 0 & 0 \\
5 & 3 & 7 & 2.33 & 0 & 0 \\
6 & 4 & 9 & 2.25 & 0 & 0.04 \\
7 & 6 & 11 & 1.83 & 1 & 0.09 \\
8 & 5 & 9 & 1.8 & 0 & 0 \\
9 & 11 & 19 & 1.72 & 2 & 0 \\
10 & 7 & 11 & 1.57 & 0 & 0 \\
11 & 3 & 9 & 3 & 0 & 0 \\
12 & 5 & 9 & 1.8 & 0 & 0 \\
13 & 4 & 9 & 2.25 & 0 & 0 \\
14 & 5 & 8 & 1.6 & 0 & 0 \\
15 & 4 & 9 & 3 & 0 & 0 \\
16 & 3 & 9 & 2.2 & 0 & 0 \\
17 & 5 & 11 & 2.25 & 0 & 0.17 \\
18 & 4 & 9 & 2.66 & 1 & 0 \\
\hline
\end{tabular}

served to spend only a small portion of time in natural feeding on tress when in wild they are frugivorous in nature. These macaque species were habituated with urban life, anthropogenic food and supplementary feeding mechanism. After their relocation, macaques were given food supply daily in the forest and their movements were restricted to the feeding platforms and towards the gates where people used bring food for macaques or these macaques often used to disperse from the sanctuary and into the outskirt houses in search of human food. In India, Rhesus macaques co-exist human population mostly and are therefore highly dependent upon human beings for food (Southwick et al., 1976). This relationship between macaques and humans are depicted in Hindu mythology. Roadside food provisioning is a common practice across the cities and villages in India.

Natural feeding was observed in the morning before the arrival of supplementary trucks of food between 06:00-8:00 hours indicated that grooming behaviour was spontaneous and occurred throughout the day. However maximum frequency was recorded before 11:00 hours in the morning and after 15:00 hours in the afternoon. Aggression, running, snatching, attack, vocalization behaviours were frequently recorded during supplementary feeding between 11:00 -15:00 hours. Macaques were seen active more in morning and evening time and juveniles were mostly involved with social play and that continued the whole day (Fig.2). Conflict was observed within different troops during feeding and some of the individuals were seen to get engaged in negative interactions with human as these macaques possessed a ten- dency towards human food. We recorded daily activity patterns in detail to understand their daily movements and spatio- temporal engagements in the sanctuary and their adaptive patterns in this new environment.

Reproductive ecology: Rhesus macaque groups are characterized by female philopatry and male dispersal, females remain in their natal groups and form dominance hierarchies according to their matrilineal kinship while males emigrate from their natal groups at the beginning of the breeding season shortly before puberty, and may transfer groups throughout their lives in search of mating opportunities (Melnick et al., 1984). The ovarian cycle lasts for 28 days and is characterized by the darkening of the skin surrounding the anogenital region accompanied by menstruation (Catchpole and Wagenen, 1975). Oestrus lasts for eight to 12 days, with the day of ovulation occurring at the midpoint of the oestrus period. Females have increased sexual activity during ovulation, exhibiting the highest number of copulations seen during the ovarian cycle (Fooden, 2000). Females reproduce from three until about 20 years of age (Rawlins and Kessler, 1986). Males reach puberty between three and 3.5 years of age but do not reach adult body size until about eight years old (Bercovitch et al., 2003). There is marked birth seasonality in rhesus macaques, with most of mating occurring in October through December and births coinciding with the end of the rainy season, or during the period of highest food abundance (Lindburg, 1971 and Qu et al., 1993). At Cayo Santiago, the mating season is much longer and begins in July and lasts until December (Chapais, 1986). During the breeding season, females enter into consort ships 
with one or more males. An individual female will spend longer amount of time in contact with, grooming, and mating with these males. Male and female rhesus macaques are promiscuous breeders, mating multiple times with multiple mates (Lindburg, 1971). Both males and females initiate these consort relationships and competition for access to mates is related to the high levels of aggression seen in rhesus macaque groups during this time of year. Gestation lasts 164 days in rhesus macaques and the inter-birth interval is between 12 and 24 months (Fooden, 2000). Habitat condition, nutrition supplements influenced high birth rate and reproductive success in females per troop. Sexual solicitation is a major aspect of reproductive behaviour strategy (Solanki et al., 2007). Various modes of mating pair solicitation occurred in relocated macaques in the morning and late afternoon in our study. Maximum births occurred during April to June and late August to October. Sexual mating was observed in solicitation and average gestation period was 160 days in Asola-Wildlife Sanctuary. We calculated total number of births occurred per female in each of the troops, birth rate per female/ year (natality) and mortality in each troop we have studied in case of urban macaques inhabiting in the sanctuary during our study period (Table 3 ). Previous studies reported about the potential of reproduction in adult females, frequency of births, birth intervals. If a female macaque does not have a successful pregnancy in certain cycle of reproductive phase or her infant dies very early in the first year of birth, then she is more likely to give birth in the following breeding season than a female who have successfully reared an infant (Seth, 2000). This has led to increase in commensal monkey population and so the man-monkey conflicts. Reproductive success of individuals depends upon their adaptive strategies, male-male competition, choice of females and feeding pattern (Bercovitch, 1997). Mating and copulation held throughout the year and social grooming between male to female and female to male increased in the breeding seasons remarkably in the month of March to June and post monsoon August to October. Frequency of post-natal care and lactation behaviour observed frequently in rhesus macaques in our study. Quality time spent on offspring care ensured the survival of young individuals and prevented the deaths of offspring after birth. Significance of this study lies in the understanding of ecology of reproductive pattern in rhesus macaques, calculation of their daily movements, influence of feeding pattern in their daily activity budget.

\section{Conclusion}

Daily activity showed variations of behavioural pattern with time significantly as these relocated macaques adopted urban environment and their high reproductive rate per female clearly indicated towards increased population rate and this could increase risk in management of urban population of rhesus macaques. This is the first case study on relocated rhesus macaques in Asola-Bhatti Wildlife Sanctuary and has potential to serve conservation action plan. This study strongly recommends to continue studying natality and mortality factors for three to five years and develop survivorship curve of population ecology. The minimum change in birth rate indicated the trend in dynamic reproductive model of rhesus macaques and it is possible to measure carrying capacity to predict the growth curve of next ten years and status of survivors. This information will help to standardize population management models for rhesus macaques in urban landscapes and reduce humanmacaque conflict remarkably. The design of our study combines both ecology and behavioural studies to resolve the issues of problematic species (involved in the negative interactions with human which increases the risk of human-animal conflict) in concern and this kind of prolonged observations can be vey useful to wildlife management team in decision making and planning of urban wildlife protection and conservation.

\section{ACKNOWLEDGEMENTS}

We would like to thank Mr. A.K. Shukla, Chief Wildlife Warden of Delhi Forest and Wildlife Department to issue permit for working in the field area, Mr. S.K Muan Giete, Deputy Conservator of Forest, South Division, Delhi for providing support and smooth conduct of field research. We would thank Prof. Dr. Praful Singh and Ms. Pradipika Verma to contribute in designing maps though GIS software and data imaging. We are thankful to World Wide Fund for Nature-small grant programme, India for providing funding support for conducting the research.

\section{REFERENCES}

1. Altmann, J. (1974). Observational study of behaviour: sampling methods. Behaviour 49: 227-267.

2. Altmann, J. (1980). Baboon mothers and infants, Cambridge: Harvard University Press.

3. Bercovitch, F. (1997). Reproductive Strategies of Rhesus Macaques. Primates 38 (3): 247-263.

4. Bercovitch, F.B., Widdig, A., Trefilov, A., Kessler, M.J., Berard, J.D., Schmidtke, J., Nurnberg, P. and Krawczak, M. (2003). A longitudinal study of agespecific reproductive out-put and body condition among male rhesus macaques, Macaca mulatta, Naturwissenschaften 90, 309-312.

5. Blomquist, Gregory E. (2013). Maternal Effects on Offspring Mortality in Rhesus Macaques (Macaca mulatta). American Journal of Primatology 75:238251.

6. Catchpole, H.R. and Van Wagenen, G. (1975). Reproduction in the rhesus monkey, Macaca mulatta. Int. J. Primatol. 2:117-140. 
7. Chalise MK (1999). Report on Assamese monkeys (Macaca assamensis) of Nepal. Asian Primates7:7-11

8. Chapais, B. (1986). Why do adult male and female rhesus monkeys affiliate during the birth season? In: Rawlins RG, Kessler MJ (eds) The Cayo Santiago Macaques. SUNY Press, Albany, 173-200.

9. Charmantier A, Garant D. (2005). Environmental quality and evolutionary potential: lessons from wild populations, Proc. R Soc Lond B, 272: 1415-1425.

10.Chauhan A. and Pirta, R.S. (2010). Public Opinion Regarding Human-Monkey Conflict in Shimla, Himachal Pradesh. Journal of Human Ecology 30(2): 105109.

11.Dufour DL, Sauther ML. (2002) Comparative and evolutionary dimensions of the energetics of human pregnancy and lactation. Am J Hum Biol 14: 584602.

12.Dunbar, R. I. M. (1988) Primates social systems. Ithaca, NY: Comstock Publishing Associates.

13.Fooden, J. (2000). Systematic review of the rhesus macaque, Macaca mulatta (Zimmermann, 1780). Field Zoology 96: 1-180.

14.Imam, E. (1995). A preliminary survey of rhesus monkey population in Vrindaban: Problems and its possible management, World Wide Fund for nature and natural resource, WWF-India, Delhi, India, p 24.

15.Imam, E., Ahmad, A. (2013). Population status of Rhesus monkey (MACACA MULATTA) and their menace: A threat for future conservation. International Journal of Environmental Sciences 3: 2013

16.Jolly, A. (1985). The evolution of primate behavior. New York: Macmillan.

17.Kays, R., Crofoot, M., Jetz, W., and Wikelski, M. (2015). Terrestrial animal tracking as an eye on life and planet. Science 348: 1222 https:// doi.org/10.1126/science.aaa

18. Keverne, E. B. (1989). Reproductive behaviour. In C. R. R. Austin V Short (Ed.) Reproduction in mammals, B-4 reproductive fitness, Cambridge: Cambridge University Press.

19.Lindburg, DG. (1971). The rhesus monkey in north India: an ecological and behavioral study in primate behaviour. Rosenblum LA (ed) 2: 1-106. New York, Academic press.

20.Maestripieri, D. (2001). Female-biased maternal investment in rhesus macaques. Folia Primatologica 72:44-47.

21.Malik I. (1986). Time budgets and activity patterns in free ranging rhesus monkeys. In: Primate Ecology and Conservation (Else, J.G. and Lee, P.C. Eds.), Cambridge University, Yew York, pp.105-114.

22.Md-Zain, B.M., Tarmizi, M.R., Mohd-Zaki, M. (2011). Campus monkeys of University Kebangsaan Malaysia: Nuisance problems and students' perceptions. In: Gumert MD, Fuentes A, Jones-Engel L (eds). Monkeys on the edge: Ecology and management of long-tailed macaques and their interface with humans. Cambridge Univ Press, Cambridge, pp 101-117

23.Melnick, D.J., Jolly, C.J. and Kidd, K.K. (1984). The genetics of a wild population of rhesus monkeys (Macaca mulatta) Genetic variability within and be- tween social groups. American J. Phys. Anthrop 63:341-360.

24.Osborne, P.E., and Glew, L. (2011). Geographical information systems and remote sensing, in: Field and Laboratory Methods in Primatology, edited by: Setchell, J. M. and Curtis, D. J., Cambridge University Press, Cambridge 69-89.

25.Qu, W.Y., Zhang, R.Z., David, M. and Southwick, C.H. (2003). Rhesus monkeys (Macaca mulatta) in the Taihang Mountains, Jiyuan county, Henan, China. International Journal of Primatology 14: 607-621.

26.Rajpurohit, L. S., Srivastava, A., \& Mohnot, S. M. (1994). Birth dynamics in Hanuman langurs, Presbytis entellus of Jodhpur. Indian Journal of Bioscience 19: 315-324.

27.Rawlins RG, Kessler MJ. (1986). Demography of the free-ranging Cayo Santiago macaques. In: Rawlins RG, Kessler MJ (eds) The Cayo Santiago macaques. SUNY Press, Albany, NY.

28.Sennhenn-Reulen, H., Diedhiou L., Klapproth M., and Zinner B. (2017). Estimation of baboon daily travel distances by means of point sampling - the magnitude of underestimation. Primate Biol. 4:143151. https://doi.org/10.5194/pb-4-143.

29.Seth, P.K. (2000). Habitat, resources, utilization, pattern and determinates behaviour in rhesus monkey. J. Hum. Ecology 11(1):1-21.

30.Sha, J.C.M., Gumert, M.D., Lee, B.P.Y-H., JonesEngel, L., Chan, S., Fuentes, A. (2009). Macaquehuman interactions and the societal perceptions of macaques in Singapore. $A m ~ J$ Primatol, 71: 825-839.

31.Singh, M. and Kaumanns, W. (2005). Behavioural studies: A necessity for wildlife management. Current science 89: 7

32.Singh, M., and Kaumanns, W. (2014). Behavioural studies, A necessity for wildlife management, Animal Behaviour. Current Science 89(7).

33.Sinha, A., Vijayakrishnan,S. (2017). Primates in Urban Settings. The International Encyclopedia of Primatology.

34.Solanki, G.S., Kumar, A., and Sharma B.K. (2007). Reproductive Strategies of Trachypithecus pileatus in Arunachal Pradesh, India. Int J Primatol 28: 10751083, http://doi.org/10.1007/s10764-007- 9204.

35.Southwick $\mathrm{CH}$, Siddiqi MF, Farooqui MY, Pal BC. (1976). The effects of artificial feeding on aggressive behaviour of rhesus monkeys in India. Animal Behaviour 24: 11-15.

36.Southwick, C.H., Siddiqi, M.F. and Oppenheimer, J.R. (1983). Twenty-year changes in rhesus monkey populations in agricultural areas of northern India. Ecology 64(3): 434-439.

37.Southwick, C.H., Teas, J., Richie, T. and Taylor, H. (1982). Ecology and behavior of rhesus monkeys (Macaca mulatta) in Nepal. Nat. Geo. Soc. Res. Rep 14: 619-630.

38.Sterling, E.J., Bynum, N., and Blair, M.E.(Eds.). (2013). Primate Ecology and Conservation, A Handbook of Techniques, Oxford University Press, Oxford.

39.Sutherland J.W. (1998). The importance of behavioural studies in conservation biology, Animal Behaviour 56: 801-809. 